\title{
Comparative bacterial degradation and detoxification of model and kraft lignin from pulp paper wastewater and its metabolites
}

\author{
Amar Abhishek $^{1,2} \cdot$ Ashish Dwivedi $^{3} \cdot$ Neeraj Tandan $^{4} \cdot$ Urwashi Kumar $^{5}$
}

Received: 9 May 2014/Accepted: 20 April 2015/Published online: 10 May 2015

(c) The Author(s) 2015. This article is published with open access at Springerlink.com

\begin{abstract}
Continuous discharge of lignin containing colored wastewater from pulp paper mill into the environment has resulted in building up their high level in various aquatic systems. In this study, the chemical texture of kraft lignin in terms of pollution parameters (COD, TOC, BOD, etc.) was quite different and approximately twofold higher as compared to model lignin at same optical density (OD 3.7 at $465 \mathrm{~nm})$ and lignin content $(2000 \mathrm{mg} / \mathrm{L})$. For comparative bacterial degradation and detoxification of model and kraft lignin two bacteria Citrobacter freundii and Serratia marcescens were isolated, screened and applied in axenic and mixed condition. Bacterial mixed culture was found to decolorize 87 and $70 \%$ model and kraft lignin (2000 mg/L), respectively; whereas, axenic culture Citrobacter freundii and Serratia marcescens decolorized 64, $60 \%$ model and 50, $55 \%$ kraft lignin, respectively, at optimized condition $\left(34{ }^{\circ} \mathrm{C}, \mathrm{pH} 8.2,140 \mathrm{rpm}\right)$. In addition, the mixed bacterial culture also showed the removal of 76 , $61 \%$ TOC; 80, $67 \%$ COD and 87, $65 \%$ lignin from
\end{abstract}

Neeraj Tandan

neeraj_tandan@yahoo.in; neerajtandan@gmail.com

1 Environmental Microbiology Section, CSIR-Indian Institute of Toxicology Research, Post Box 80, M. G. Marg,

Lucknow 226001, Uttar Pradesh, India

2 Department of Urology, King George's Medical University, Lucknow 226003, Uttar Pradesh, India

3 Phototoxicity Division, CSIR-Indian Institute of Toxicology Research, Post Box No. 80, M. G. Marg, Lucknow 226001, Uttar Pradesh, India

4 Scientific and Applied Research Center, Post Box No. 2241, Meerut 250001, Uttar Pradesh, India

5 International Centre for Genetic Engineering and Biotechnology, P. O. Box 10504, Aruna Asaf Ali Marg, New Delhi 110067, India model and kraft lignin, respectively. High pollution parameters (like TOC, COD, BOD, sulphate) and toxic chemicals slow down the degradation of kraft lignin as compared to model lignin. The comparative GC-MS analysis has suggested that the interspecies collaboration, i.e., each bacterial strain in culture medium has cumulative enhancing effect on growth, and degradation of lignin rather than inhibition. Furthermore, toxicity evaluation on human keratinocyte cell line after bacterial treatment has supported the degradation and detoxification of model and kraft lignin.

Keywords Bacteria - Kraft lignin - GC-MS - Toxicity · Cell line

\section{Introduction}

The increasing scarcity of water in the world caused by the steady growth of the population and the industrial development raises serious concerns about the need for appropriate water management practices. The pulp paper mills are water-intensive industries generating several types of wastewater with different characteristics, depending on the production process and its raw material. Most significant sources of pollutants in pulp paper mills are wood preparation, pulping, bleaching and coating processes. The color of pulp paper wastewater is mainly due to lignin and its derivatives, which causes various problems along with aesthetically unacceptable intense coloring of water bodies, which block the passage of light to the lower depths of the aquatic system resulting in cessation of photosynthesis, leading to anaerobic conditions, which in turn result in the death of aquatic life causing foul smelling and toxicity of waters bodies (Ali and Sreekrishnan 2001). Thus, it is 
obligatory to treat the wastewater adequately before final disposal into the environment. Despite the fact that, several physical and chemical methods are available for the treatment of wastewater, they are less desirable than biological process because of cost-ineffectiveness and residual effect (Singhal and Thakur 2009).

Microorganisms are nature's innovative recyclers, converting toxic organic compounds to innocuous species. Among biological treatment methods tried so far, most of the literature confined to a few genera of white rot fungi because of their powerful enzymatic system. But, the stability of fungi is not good in practical treatment under extreme environmental and substrate conditions, such as higher $\mathrm{pH}$, oxygen limitation, and high lignin concentrations. On the other hand, the bacterial ability to use low molecular weight fraction of lignin indicated that bacteria have many unique and specific enzymes with the ability to catalyze the production of various useful compounds (Masai et al. 1999; Raj et al. 2007). In lignin bioremediation, synthetic/model lignin has been widely used as an experimental lignin (Forney and Reddy 1979; Perestelo et al. 1989; Morii et al. 1995; Raj et al. 2007). But, kraft lignin (KL) which is present in pulp paper wastewater differs from model lignin (ML) as it undergoes a variety of reactions including aryl-alkyl cleavages, strong modification of side chains, and various illdefined condensation reactions causing the polymer to fragment into smaller water/alkali-soluble fragments (Chakar and Ragauskas 2004). However, the above studies provide indirect evidence for the degradation of lignin or its model compounds that cannot be directly explain the degradation of KL. Therefore, there is a need for the comparative study of bacterial removal of ML and KL simultaneously, to explore the inhibitory factors responsible for poor/less degradation of lignin. For this reason, there is still a need for continued search for more efficient ligninolytic bacterial strains for the lignin bioremediation.

Due to the diversity of pollutants in pulp paper mill wastewater, their control is very difficult and presence in water resources poses a high risk to the environment as well as human health. Several studies reported that the pollutants present in pulp paper mill wastewater are responsible for the oxidative stress, DNA damage and lipid peroxidation which leads to apoptosis. Moreover, terpenoids, phytosterols, 2-methoxyphenol and related compounds have been identified as a potential source of cytotoxicity caused by paper mill wastewaters (Chamorro et al. 2013). Therefore, the in present investigates a potential bacterial strain was isolated and screened from pulp and paper mill sludge and examined its ability to decolorize/degrade lignin, which is a major challenge for the pulping industry and characterization of its metabolic products. Furthermore, the study has been extended to assess the cytotoxicity and intracellular reactive oxygen species (ROS) generation using human cell line for evaluation whether toxicity increases or reduces.

\section{Methods}

\section{Sampling site, sample collection and analysis}

The wastewater and sludge samples were collected from M/s Yash paper mill Ltd., Darsannagar, Faizabad (UP), India, having co-ordinates $26^{\circ} 44^{\prime} 20^{\prime \prime} \mathrm{N}$ latitude and $82^{\circ} 13^{\prime} 42^{\prime \prime} \mathrm{E}$ longitude. This industry came into operation in 1982 and uses eucalyptus, wheat straw and sugarcane bagasse as a raw material and adopts kraft process for pulping followed by multistage chlorine bleaching for making white paper. The wastewater was collected from pulping stage in sterile plastic containers, brought to laboratory and stored at $4{ }^{\circ} \mathrm{C}$ for further study. The physico-chemical parameters were accomplished as described in standard methods for the examination of water and wastewaters (APHA 2005). The $\mathrm{pH}$ of the sample was analyzed with the selective ion electrode $(9172 \mathrm{BN})$ of Thermo Orion (Model 960). Model lignin (ML) was purchased from Sigma Aldrich (USA), whereas the kraft lignin (KL) was extracted from pulp paper mill wastewater by precipitation method (Raj et al. 2007).

\section{Media composition and source of microorganism}

The medium used throughout this study was lignin-amended mineral salt medium (MSM), which contained (mg/L): [lignin, 2000; $\mathrm{K}_{2} \mathrm{HPO}_{4}, 85 ; \mathrm{KH}_{2} \mathrm{PO}_{4}, 17 ; \mathrm{MgSO}_{4}$, $30 ; \mathrm{FeSO}_{4} \cdot 7 \mathrm{H}_{2} \mathrm{O}, 30 ; \mathrm{CaSO}_{4}, 30 ; \mathrm{MnSO}_{4} \cdot \mathrm{H}_{2} \mathrm{O}, 30 ;\left(\mathrm{NH}_{4}\right)_{2}$ $\mathrm{SO}_{4}$, (Chandra et al. 2011)]. For comparative study both lignins $(2000 \mathrm{mg} / \mathrm{L}$, w/v) were added separately to the liquid medium in such a way to give an optical density 3.7 at $465 \mathrm{~nm}$ with the reference of distilled water as a blank and $\mathrm{pH}$ was adjusted to 8.2 .

For degradation study, potential bacteria were isolated from the sludge of main drainage of pulp paper industry with regular discharge of their wastewater. A stable bacterial community was obtained after enrichment of microbial cell. Ten purified isolated bacterial strains designated as SU1-SU10 were screened on the basis of their COD, color and lignin-removal potential (Chandra and Abhishek 2011). Two potential bacterial strains (SU1 and SU5) showing rapid growth and reduction of pollution parameters were selected for further study. For the construction of effective bacterial co-culture, the screened strains were tested in mixed condition. Further, the identification of strains was established on the basis of morphological and biochemical characteristics (Barrow and Feltham 1993). 


\section{Removal of model and kraft lignin by axenic and mixed bacterial culture}

For degradation study, $2 \%(\mathrm{v} / \mathrm{v})$ overnight-grown suspension of SU1 and SU5 having inoculum size $22 \times 10^{4}$ and $30 \times 10^{4}$, respectively, was transferred aseptically to 250-mL flask containing $98 \mathrm{~mL}$ MSM medium containing $2000 \mathrm{mg} / \mathrm{L}$ lignin, amended with $1 \%$ glucose and $0.3 \%$ peptone $(\mathrm{w} / \mathrm{v})$ at $\mathrm{pH}$ 8.2. Similarly, in mixed condition, $1 \%(\mathrm{v} / \mathrm{v})$ from each culture was added to obtain final inoculum size $2 \%(\mathrm{v} / \mathrm{v})$ in same condition. The inoculated flasks were incubated at $34 \pm 2{ }^{\circ} \mathrm{C}$ under shaking flask condition (140 rpm) for 6 days. The bacterial growth was measured at $620 \mathrm{~nm}$ using uninoculated medium as blank. For the measurement of color and residual lignin, bacterial degraded and undegraded samples were centrifuged at $8000 \mathrm{~g}$ for $30 \mathrm{~min}$. Supernatant $(1 \mathrm{~mL})$ was diluted by adding $3 \mathrm{~mL}$ phosphate buffer ( $\mathrm{pH}$ 7.6) and absorbance measured at $465 \mathrm{~nm}$ for color reduction and at $280 \mathrm{~nm}$ for lignin degradation on a UV-visible spectrophotometer. To confirm whether the decolorization/degradation process was biological or adsorption phenomenon, $\mathrm{NaOH}$ extraction method was adopted (Jiranuntipon et al. 2008). The residual pellets of bacteria were resuspended in equal volume of $\mathrm{NaOH}(0.1 \mathrm{M})$ to extract color substances adsorbed to the cell surface. The extracts were centrifuged and absorbance was measured at $465 \mathrm{~nm}$.

\section{Metabolite characterization}

Bacterial undegraded and degraded samples $(50 \mathrm{~mL})$ were centrifuged at $3000 \mathrm{~g}$ for $20 \mathrm{~min}$. The supernatant obtained was acidified to $\mathrm{pH} 2.0$ using $1 \mathrm{~N} \mathrm{HCl}$ and extracted thrice with the equal volume $(50 \mathrm{~mL})$ of ethyl acetate in a separating funnel $(500 \mathrm{~mL})$ by intermittent shaking. The organic layer was separated and evaporated to dryness under vacuum at $40{ }^{\circ} \mathrm{C}$. Further, the residues were dried under a stream of nitrogen gas and dissolved in acetonitrile for GC-MS analysis and de-ionized water for toxicity evaluation.

An aliquot of $1 \mu \mathrm{l}$ of silylated compounds was injected into the GC-MS equipped with a PE auto system XL gas chromatograph interfaced with a turbomass mass spectrometric mass selective detector. The analytical column connected to the system was a PE-5MS capillary column (20 $\mathrm{m} \times 0.18 \mathrm{~mm}$ i.d., $0.18 \mu \mathrm{m}$ film thickness). Helium gas with flow rate of $1 \mathrm{~mL} / \mathrm{min}$ was used as carrier gas. The column temperature was programmed as $50{ }^{\circ} \mathrm{C}(5 \mathrm{~min})$; 50-300 ${ }^{\circ} \mathrm{C}\left(10{ }^{\circ} \mathrm{C} / \mathrm{min}\right.$, hold time: $\left.5 \mathrm{~min}\right)$ (Chandra and Abhishek 2011). The metabolic products were identified by comparing their mass spectra with that of NIST library available with instrument and by comparing the retention time with those of available authentic organic compounds.

\section{Toxicity evaluation}

Acute toxicity test was performed to evaluate the reactive oxygen species (ROS) generation and cytotoxicity by using human keratinocyte (HaCaT) cell line. The cell line was grown in DMEM F-12 HAM media supplemented with $10 \%$ FBS, antibiotics and antimycotic solution $(1.5 \%)$ at $5 \% \mathrm{CO}_{2}$ and $95 \%$ relative humidity at $37{ }^{\circ} \mathrm{C}$ (Agrawal et al. 2007).

\section{Determination of intracellular ROS production}

Cells were grown in 96-multiwell black plates $\left(2 \times 10^{4}\right.$ cells/well) and treated with four types of samples $(50 \mu \mathrm{l})$ extracted from undegraded and degraded samples of ML and $\mathrm{KL}$, respectively. Cells were then incubated for $30 \mathrm{~min}$ at $37{ }^{\circ} \mathrm{C}$ with $10 \mu \mathrm{M}$ carboxy H2-DCFDA (dichlorofluorescin diacetate) in HBSS (Hank's balanced salt solution) and exposed. Culture medium was used as a control (C). After treatment the cells were incubate for $24 \mathrm{~h}$. The fluorescence of DCF was measured by using $485 \mathrm{~nm}$ excitation and $520 \mathrm{~nm}$ emission wavelengths. The generation of intracellular ROS was further substantiated by the administration of NAC ( $N$-acetyl cysteine) $(10$ and $100 \mu \mathrm{M})$ as a specific quencher (Valencia and Kochevar 2006).

\section{Cell viability assay by MTT}

In brief, cells $\left(2 \times 10^{4}\right)$ were seeded per well in 96-well plates and kept in $\mathrm{CO}_{2}$ incubator for $48 \mathrm{~h}$. The treatments were performed with four different sample extracts $(50 \mu \mathrm{L})$ by complete medium $(200 \mu \mathrm{L})$ and incubated for $24 \mathrm{~h}$. Further, the media were replaced by 3-(4,5-dimethylthiozolyl-2)-2,5-diphenyl tetrazolium bromide (MTT) (5 mg/ $\mathrm{mL}$ ). The absorbance was recorded at $530 \mathrm{~nm}$ by using multiwell micro plate reader (Agrawal et al. 2007).

\section{Results}

\section{Characterization of the isolated bacterial strain}

The chemical texture of ML and KL at same optical density and lignin concentration was quite different in nature, which was noted as $\mathrm{pH}: 8.2,8.2$; sulphate: 4.7, 211; color: 6700, 6700 Co.pt; COD: 8068, 16,700 mg/L; BOD: 3018, $6080 \mathrm{mg} / \mathrm{L}$; TOC: 3130, 6250; lignin: 2000, $2000 \mathrm{mg} / \mathrm{L}$, respectively. This was indicated that $\mathrm{KL}$ found in paper mill effluent was very different in nature. In this study, two bacterial strains SU1 and SU5 were found to be very efficient and could reduce 45,41 and 33, $31 \%$, COD and 52, 57 and 48, $52 \%$ color in ML and KL, respectively, during 6 days of incubation period. Further, on the basis of 
Table 1 Bio-chemical characterization of screened bacterial strains

\begin{tabular}{lll}
\hline Characteristics & SU1 & SU5 \\
\hline Gram reaction & - ve & -ve \\
Shape & Rod & Rod \\
Culture & Translucent, moist, & Opaque, round, and \\
characteristic on & medium, round & produces red pigment \\
agar plate & & - \\
Growth of & - & \\
MacConkey agar & & - \\
Urea & - & - / \\
MR/VP & + - & + \\
Gelatin & - & - \\
Oxidase & - & + \\
Catalase & + & - \\
Starch hydrolysis & - & + \\
Citrate utilization & + & + \\
Motility & + & - \\
Indole & - & - \\
H 2 S & - & A \\
Carbohydrate fermentation & A/G & - \\
Glucose & A & \\
Sucrose & A & \\
Lactose & & \\
\hline
\end{tabular}

- negative, + positive, $A$ acid, $G$ gas

biochemical tests both the strains were found, gram-negative rods and belong to Enterobacteriaceae family. In addition, strain SU1 was motile, gram-negative rod-shaped bacteria and gave positive test for oxidase and catalase; whereas, strain SU5 was differentiated from SU1 produces a reddish-orange pigment. Finally, these two bacteria (SU1 and SU5) were identified as Citrobacter freundii and Serratia marcescens, respectively, (Table 1).

\section{Comparative removal of model and kraft lignin}

Bacterial growth, measured by absorbance at $620 \mathrm{~nm}$ showed the optimum growth at 4th day of incubation period during lignin degradation (Fig. 1a, b). The $\mathrm{pH}$ decline tendency of the medium during degradation was recorded at 2nd day; which subsequent increases to a level of neutral at the end of experiment (Fig. 1a, b). Results revealed that mixed bacterial culture was found to be more effective than axenic culture for lignin degradation as well as remove 76 , $61 \%$ TOC; 80, $67 \%$ COD and 87, $65 \%$ lignin from ML and KL, respectively (Fig. 2a, b). In addition, to confirm that lignin degradation is a biological phenomenon not adsorption, suspended bacterial pellet was dissolved in $\mathrm{NaOH}$ solution. It showed that the fraction of $\mathrm{NaOH}-\mathrm{ex}-$ tractable color substances were negligible (Fig. 2c). Hence, the results clearly indicated that lignin degradation process was a completely biological phenomenon.
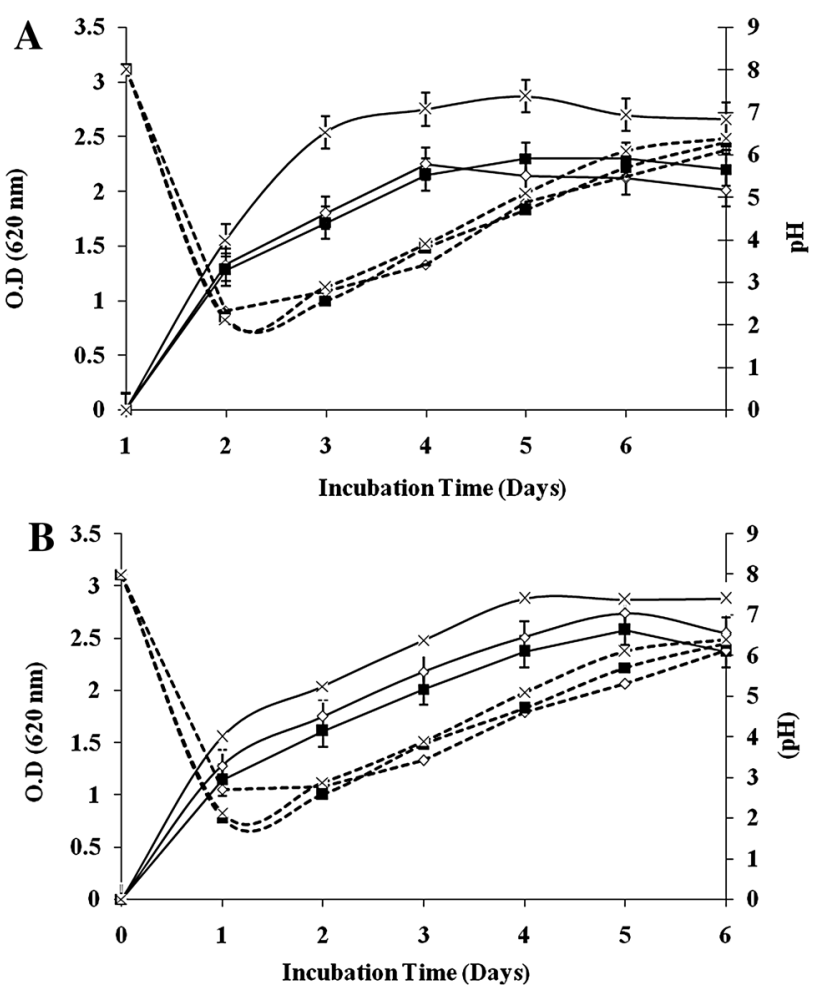

Fig. 1 Bacterial growth and pH pattern of model lignin (ML) (a) and kraft lignin (KL) (b). Error bar represents standard deviation. COD chemical oxygen demand, TOC total organic carbon

\section{GC-MS analysis}

Results obtained for comparative degradation of ML and KL through GC-MS analysis of the ethyl extracted products showed the massive consumption of compounds as compared to their respective controls (Fig. 3). Many organic compounds were detected in control sample of ML such as guaiacol (RT-12.9); benzoic acid (RT-13.8); phthalic anhydride (RT-15.5); butylated hydroxytoluene (RT17.1); 1,2,3-trihydroxy propane (RT-19.2); vanillin acid (20.5); dibutyl phthalate (21.5); octadecanoic acid (26.4) and benzyl butyl phthalate (RT-28.1) were diminished after bacterial treatment (Table 2); whereas, in KL control sample some different but lignin-related fragments were identified such as acetic acid (RT-9.55); phthalate (RT18.2); butanoic acid (RT-25.4); propyl benzene (RT-30.4) were identified. In addition to lignin fragments, some chlorophenols such as 3,4,5-trichlorophenol (RT-16.0); 2,3,4,6-tetrachlorophenol (RT-18.8) and pentachlorophenol (RT-21.8) were found in kraft lignin undegraded (control) and degraded samples by axenic culture, whereas in mixed condition these chlorophenols were not identified using NIST database. These data indicated that, the developed mixed bacterial culture showed better overall removal efficiencies than axenic culture. While on the other hand, some compounds such as hexadecanoic acid and phthalate 
Fig. 2 Reduction of pollution parameters of ML (model lignin) (a) and KL (kraft lignin) (b); and adsorption vs degradation during bacterial degradation by mixed culture
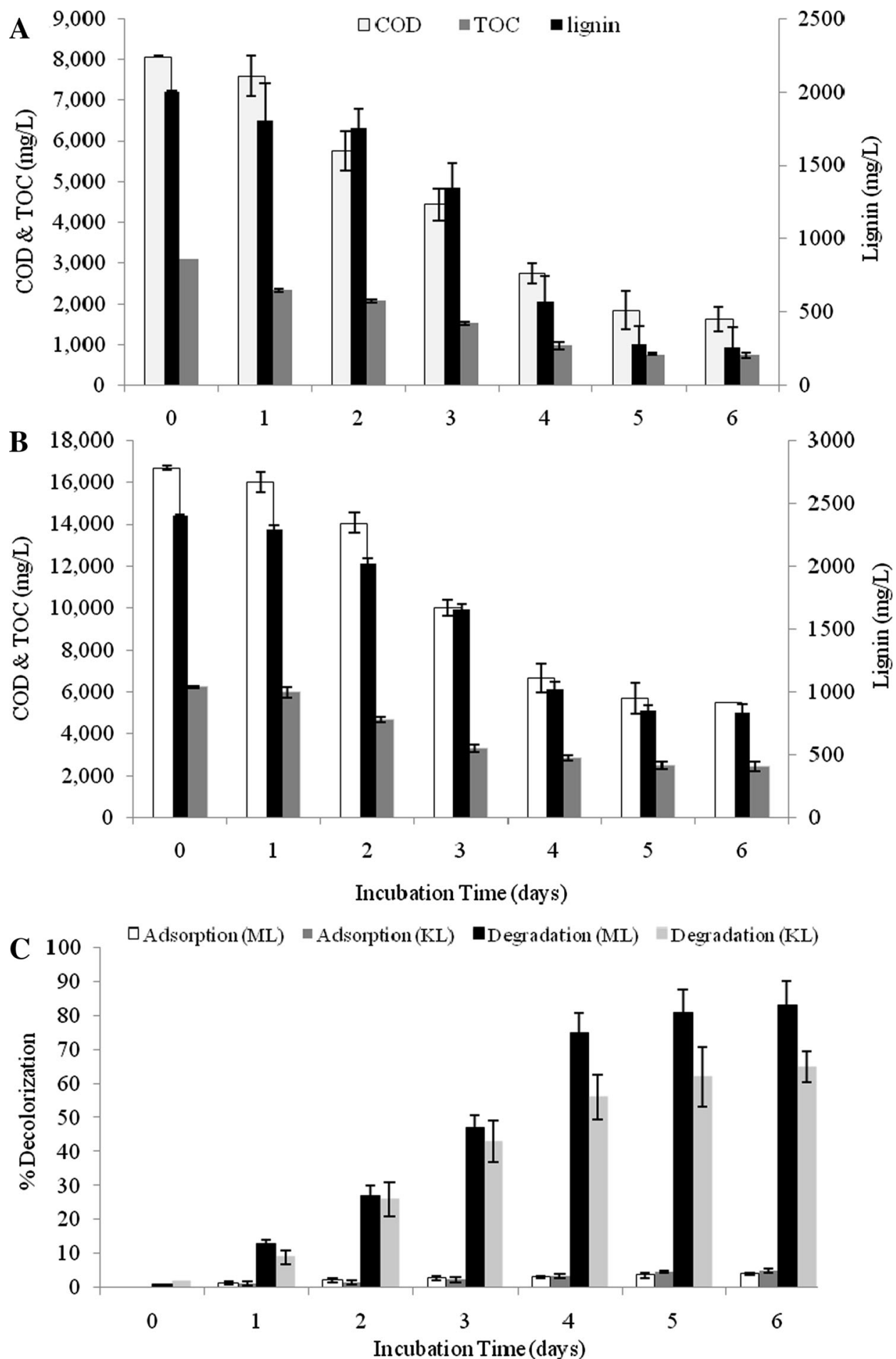

in case of model lignin and kraft lignin, respectively, remain unchanged (Table 3).

\section{Intracellular ROS generation}

Intracellular ROS levels generated by different sample extract were measured by using DCF assay (Fig. 4). The undegraded sample of KL (control) revealed the maximum generation of ROS than other samples. The generation of ROS is following order, medium control $<$ degraded sample of $\mathrm{ML}<$ degraded sample of $\mathrm{KL}<$ undegraded sample of $\mathrm{ML}<$ undegraded sample of KL (Fig. 4a). Further, quenching of intracellular ROS generation of undegraded sample of KL by different concentrations of NAC 


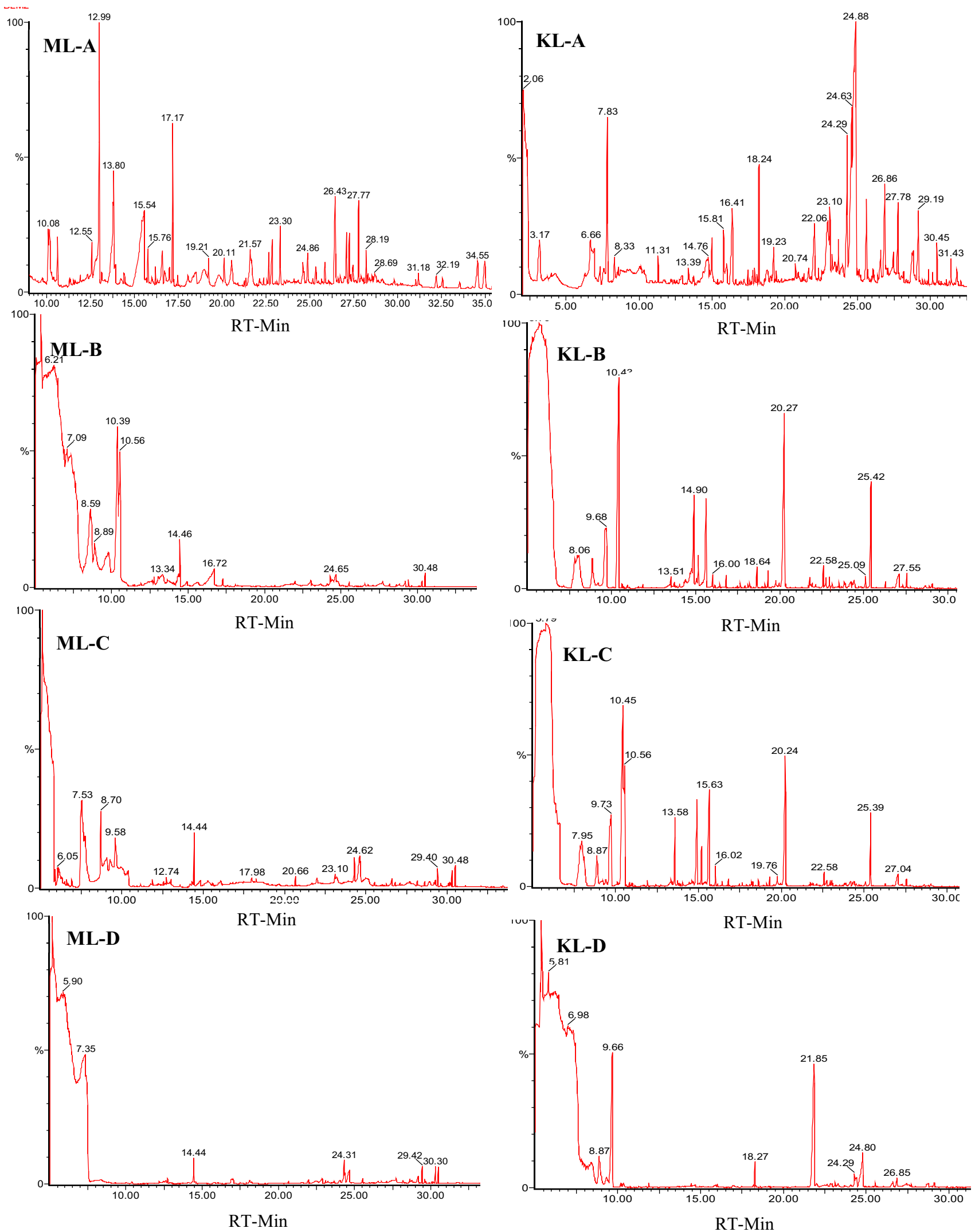

Fig. 3 Total ion chromatogram (TIC) of ethyl acetate extracts from undegraded (a) and degraded samples of model (ML) and kraft lignin (KL) with SU1 (b); SU5 (c) and mixed bacterial culture (d) 
Table 2 Compounds identified as TMS derivatives in ethyl acetate extract from control and bacterial degraded samples of model lignin

\begin{tabular}{|c|c|c|c|c|c|c|}
\hline \multirow[t]{2}{*}{ S. no. } & \multirow[t]{2}{*}{ Compounds } & \multicolumn{5}{|c|}{ Model lignin } \\
\hline & & R.T & a & $\mathrm{b}$ & $\mathrm{c}$ & $\mathrm{d}$ \\
\hline 1 & Propanoic acid & 10.3 & - & + & - & - \\
\hline 2 & Guaiacol & 12.9 & + & - & + & - \\
\hline 3 & Phenyl acetic acid & 13.3 & - & + & - & - \\
\hline 4 & Benzoic acid & 13.8 & + & - & - & - \\
\hline 5 & Benzyl benzoate & 14.4 & - & + & + & + \\
\hline 6 & Phthalic anhydride & 15.5 & + & - & - & - \\
\hline 7 & Homovanillic acid & 16.7 & - & + & - & - \\
\hline 8 & Butylated hydroxytoluene & 17.1 & + & - & - & - \\
\hline 9 & Gloxylic acid & 17.9 & - & - & + & - \\
\hline 10 & 1,2,3-Trihydroxy propane & 19.2 & + & - & - & - \\
\hline 11 & Vanillin acid & 20.5 & + & - & + & - \\
\hline 12 & Dibutyl phthalate & 21.5 & + & - & - & - \\
\hline 13 & Tetradecanoic acid & 23.1 & - & - & + & - \\
\hline 14 & Hexadecanoic acid & 24.8 & + & + & + & + \\
\hline 15 & Octadecanoic acid & 26.4 & + & - & - & - \\
\hline 16 & Unidentified compound & 27.7 & + & - & - & - \\
\hline 17 & Benzyl butyl phthalate & 28.1 & + & - & - & - \\
\hline 18 & 1-Phenanthrene carboxylic acid & 29.4 & - & - & + & + \\
\hline 19 & Bis (2-ethylhexyl) phthalate & 30.4 & - & + & + & + \\
\hline
\end{tabular}

$a$ control (untreated), $b$ SU1, $c$ SU5, $d$ mixed culture, $R T$ retention time in minutes, + present, - absent

Table 3 Compounds identified as TMS derivatives in ethyl acetate extract from control and bacterial degraded samples of kraft lignin

\begin{tabular}{|c|c|c|c|c|c|c|}
\hline \multirow[t]{2}{*}{ S. no. } & \multirow[t]{2}{*}{ Compounds } & \multicolumn{5}{|c|}{ Kraft lignin } \\
\hline & & R.T & a & $\mathrm{b}$ & $\mathrm{c}$ & $\mathrm{d}$ \\
\hline 1 & Ethanedioic acid & 7.83 & + & - & - & - \\
\hline 2 & Acetic acid & 9.55 & - & + & + & + \\
\hline 3 & Propanoic acid & 10.4 & + & + & - & + \\
\hline 4 & 3,4,6-Trichloro phenol & 11.5 & + & - & - & - \\
\hline 5 & Unidentified compound & 14.9 & + & + & - & - \\
\hline 6 & Phthalic anhydride & 15.6 & + & + & + & - \\
\hline 7 & 3,4,5 Trichloro phenol & 16.0 & + & + & + & - \\
\hline 8 & Phthalate & 18.2 & + & + & + & + \\
\hline 9 & 2,3,4,6-Tetrachloro phenol & 19.7 & + & - & + & \\
\hline 10 & Vanillin acid & 20.2 & + & + & + & - \\
\hline 11 & Pentachlorophenol & 21.8 & + & - & + & - \\
\hline 12 & Tetradecanoic acid & 22.5 & + & + & + & - \\
\hline 13 & Unidentified compound & 23.1 & + & - & - & - \\
\hline 14 & Hexadecanoic acid & 24.2 & + & - & + & - \\
\hline 15 & Unidentified compound & 24.8 & + & - & - & - \\
\hline 16 & Butanoic acid & 25.4 & - & + & - & + \\
\hline 17 & Octadecanoic acid & 27.0 & + & + & + & - \\
\hline 18 & Propyl benzene & 30.4 & + & - & - & - \\
\hline
\end{tabular}

$a$ control (untreated), $b$ SU1, $c$ SU5, $d$ mixed culture, $R T$ Retention Time in minutes, + present, - absent 
Fig. 4 Intracellular reactive oxygen species generation on $\mathrm{HaCaT}$ cell line after $24 \mathrm{~h}$ incubation by extracts of undegraded and degraded sample of kraft lignin (KL) and model lignin (ML) (a).

Quenching of intracellular ROS by different concentrations of $N$-acetyl-L-cysteine $(10-100 \mu \mathrm{M})(\mathbf{c})$. Qualitative analysis of DCF fluorescence under different conditions (b, d)
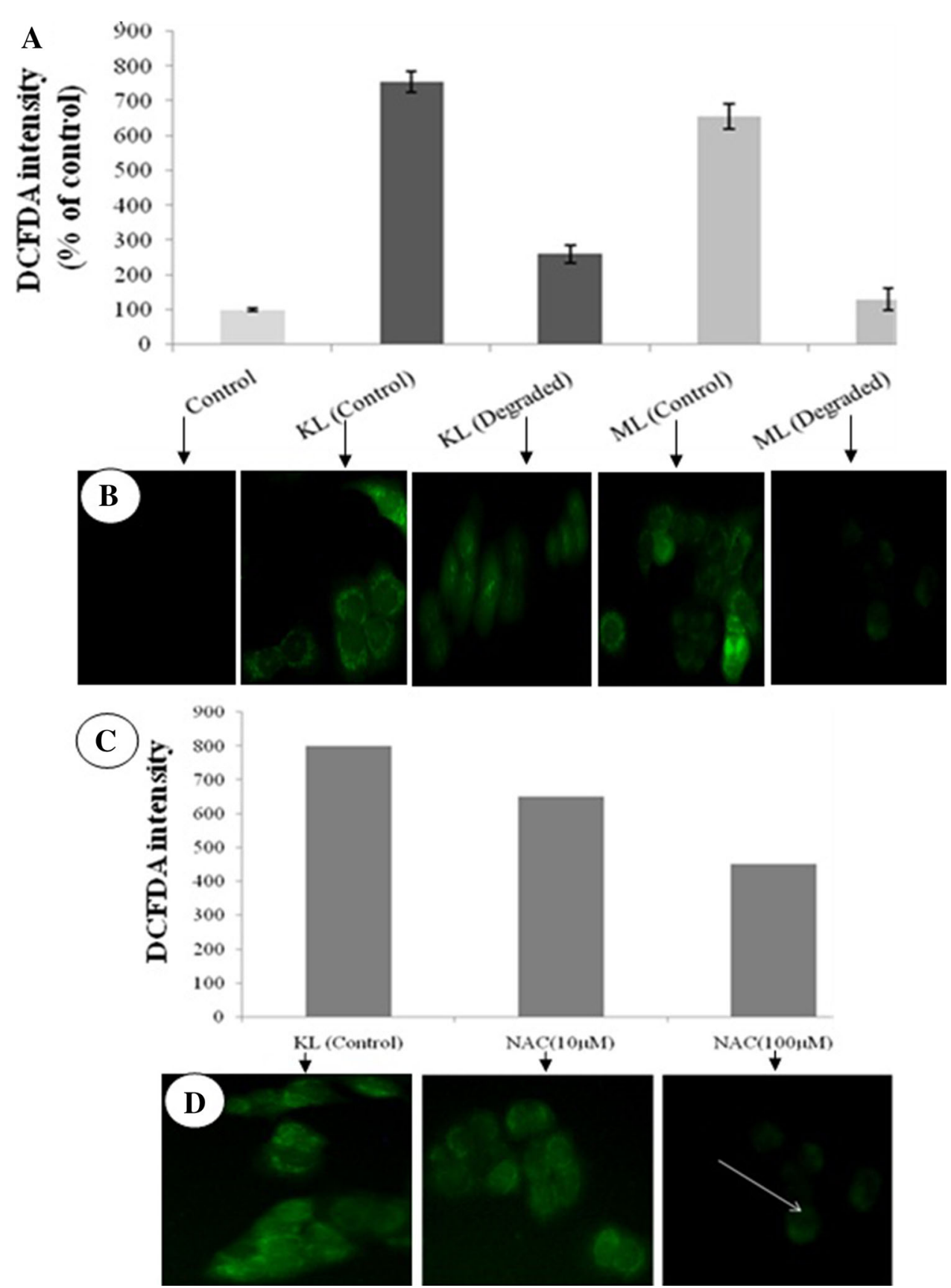

(10 and $100 \mu \mathrm{M}$ ) showed that DCF fluorescence was decreased as the concentration of NAC increased (Fig. 4c). Figure 4b, d exhibited fluorescent photographs of different conditions, which also support the above results.

\section{Cytotoxicity}

The cytotoxicity of degraded and undegraded lignin sample extracts on HaCaT cell line was performed through MTT assay. The result of MTT showed highest reduction in cell viability $(60 \%)$ by undegraded sample of KL extract than control. However, undegraded sample of ML, degraded sample of KL and degraded sample of ML showed reduction in cell viability in 40,30 and $10 \%$ than control, respectively (Fig. 5).

\section{Discussion}

Pulp paper industry has been considered as one of the biggest consumers of natural resources (wood, water) and energy (fossil fuels and electricity). These industries also considered as a significant taxpayer of discharge of pollutants to the environment. The high $\mathrm{pH}$ and sulphate value 


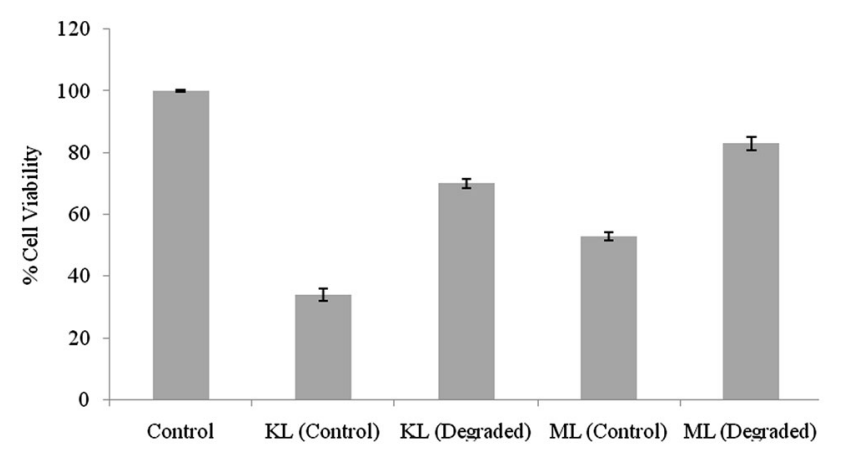

Fig. 5 Cytotoxicity of control and degraded sample of kraft lignin (KL) and model lignin (ML) extracts was performed on HaCaT cell line by MTT assay after incubation of $24 \mathrm{~h}$

of kraft lignin was due to the presence of sodium hydroxide and sodium sulphide which is used in pulping process. Besides this, the compounds with high molecular weight, such as lignin, chlorophenols and its derivatives do not affect BOD, but would contribute high COD that why these values were higher in KL compared to ML (Ugurlu et al. 2008; Chandra et al. 2011). In addition, the presence of other pollution parameters like high TOC and sulphate values in kraft lignin has made more complex than model lignin. Many authors have reported that the Citrobacter sp. and Serratia marcescens showing good potential for the degradation of various azo, anthraquinone and other toxic pollutants (Wang et al. 2009; Khalid et al. 2009). Despite the good degrading potential, these organisms have not been used for the treatment of pulp paper wastewater.

During the bacterial degradation of ML and KL, the axenic and mixed bacterial culture attained maximum growth at 4th day of incubation period in terms of optical density at $620 \mathrm{~nm}$. Results revealed that the mixed bacterial culture was found to be more effective for the removal of lignin. Low decolorization at initial phase in spite of fast bacterial growth might be possible due to the utilization of simpler form of carbon (glucose) and nitrogen source (peptone) available in growth media, but depletion of these sources from media compelled bacteria to utilize lignin as a co-substrate (Das et al. 2012). Similar to this study, a co-metabolism mechanism in bacteria and fungi during lignin degradation of kraft pine lignin and model lignin (DHP) has been reported (Perestelo et al. 1989; Kirk et al. 1978; Raj et al. 2007). During bacterial degradation the shift in $\mathrm{pH}$ towards acidic condition was noted within initial 2 days of bacterial growth which indicated the formation of acidic compounds through tricarboxylic acid (TCA) cycle, utilizing the simpler form of carbon sources present in medium by bacteria (Yang et al. 2008). As the supplementary nutritional source depleted, the $\mathrm{pH}$ of medium shifted towards higher value facilitating the lignin degradation, as lignins are uniformly soluble at high $\mathrm{pH}$ which is why more reduction in pollution parameters were noted during late stage of degradation. Similar observation during the microbial degradation of alkali lignin and pulp paper mill wastewater has also been reported (Yang et al. 2008; Singhal and Thakur 2009; Chandra et al. 2011). The treatment with mixed bacterial culture has revealed that presence of each bacterial strain in culture medium has cumulative enhancing effect on growth, and degradation of lignin rather than inhibition.

Pulp paper wastewater is a complex aqueous system; it is difficult to comprehensively investigate the changes during the degradation process. Many studies only focused on optimizing the processes itself while only few reports emphasized on the compositional changes during the biotreatment process. In the present work, phenolic units derived from lignin and some natural compounds were detected by GC/MS. The low molecular weight compounds like vanillin acid, 1-phenanthrene carboxylic acid, bis (2ethylhexyl) phthalate, etc., were derivatives of phenolic unit of lignin and could be consumed by mixed bacterial culture to a large extent (Raj et al. 2007; Ko et al. 2009). The massive consumption of these compounds were found in degraded sample of model lignin and kraft lignin as compared with its control indicated that the mixed bacterial culture have strong ability to utilize its constituents as sole source of carbon, nitrogen and energy. Coincident with earlier reports (Gupta et al. 2001), apart from these aromatic compounds, more acid-type compounds like propanoic acid, benzoic acid, gloxylic acid, hexadecanoic acid, etc., were detected than aldehyde and ketone-type due to degradation of lignin in both ML and KL. The phthalate derivative [bis (2-ethylhexyl) phthalate] had been detected from fungal peroxidase degradation of lignosulfonate (Shin and Lee 1999) and also from photodegradation of black liquor lignin (Ksibi et al. 2003). On the other hand, compounds such as hexadecanoic acid in case of model lignin remain undegraded. Unfortunately, there were also many compounds like RT-27.7 in model lignin and RT-14.9, 19.7 and 23.3 in kraft lignin that could not be identified by mass spectrometry. Along with lignin fragments some chlorophenols such as 3,4,5-trichlorophenol (RT-16.0); 2,3,4,6-tetrachlorophenol (RT-18.8) and pentachlorophenol (RT-21.8) found in kraft lignin control and degraded samples by axenic culture. However, these chlorophenols are not found in mixed bacterial culture because these might be utilized as carbon and energy source. Chlorophenols are not the fragment of lignin; it is a priority pollutant that has been used widely as a general biocide in commercial wood treatment (Lee and Wang 2006) and it probably comes during the extraction of lignin from pulp paper wastewater because at low $\mathrm{pH}$, lignin and chlorophenol both are precipitated. These findings revealed that the slow degradation of KL compared to ML due to the 
high pollution load in terms of COD, TOC, sulphate, etc., and toxic chemicals (organochlorines).

The discharge of this pulp paper mill wastewater may promote skin diseases in human beings who are directly or indirectly contact with this aquatic system (Das et al. 2012). Therefore, it is important to assess the toxic response of these pollutants by using human skin cell line as a model. The cytotoxicity assay of different lignin sample extracts on HaCaT cell line showed highest reduction in cell viability of undegraded sample of KL extract than control, which indicates the maximum pollution load in kraft lignin which was extracted from effluent released by pulp paper mill and is more hazardous for the people.

However, degraded samples of ML and KL showed a significant reduction in cell viability than control illustrating that the toxicity was decreased. Further, to evaluate the mechanism of pollutants inside the cell, intracellular ROS were performed to observe the generation of ROS. Generally, high pollution load increase the reactive oxygen species level inside the cell, which damage different cell organelles which further promote apoptosis (Lee et al. 2002). The DCFDA fluorescence is a very sensitive method to detect the ROS level inside the cell. Here our results of DCFDA on HaCaT cell line showed that as the concentration of pollutants increases, the intracellular ROS is also increases thereby increasing the fluorescence. The extract of undegraded sample of KL showed maximum fluorescence due to high pollution and degraded samples showed lesser. Further, pretreatment with NAC significantly attenuates the fluorescence intensity of DCF, which confirmed the involvement of ROS in cytotoxicity.

\section{Conclusion}

The bacterial cultures were able to co-metabolically remove lignin, using glucose and peptone as primary source of nutrients. The developed mixed bacterial culture showed better removal efficiency compared to axenic culture. Further, the GC-MS analysis of bacterial degraded samples of ML and KL has shown that presence of each bacterial strain in culture medium has cumulative enhancing effect on growth, lignin degradation and detoxification rather than inhibition. It is our view, the above information would be useful for modeling and designing the unit for the treatment of lignin containing wastewater.

Acknowledgments The authors are thankful and gratefully acknowledge the Director, CSIR-Indian Institute of Toxicology Research, for providing constant support for this work.

Conflict of interest None.
Open Access This article is distributed under the terms of the Creative Commons Attribution 4.0 International License (http:// creativecommons.org/licenses/by/4.0/), which permits unrestricted use, distribution, and reproduction in any medium, provided you give appropriate credit to the original author(s) and the source, provide a link to the Creative Commons license, and indicate if changes were made.

\section{References}

Agrawal N, Ray RS, Farooq M, Pant AB, Hans RK (2007) Photosensitizing potential of ciprofloxacin at ambient level of UV radiation. Photochem Photobiol 83:1226-1236

Ali M, Sreekrishnan TR (2001) Aquatic toxicity from pulp mill effluents: a review. Adv Environ Res 5:175-196

APHA (2005) Standard methods for the examination of water and wastewater, 21st edn. American Public Health Association, Washington, DC

Barrow GI, Feltham RKA (1993) Cowan and Steel's Manual for the Identification of Medical Bacteria, 3rd edn. Cambridge University Press, Great Britain

Chakar SF, Ragauskas JA (2004) Review of current and future softwood kraft lignin process chemistry. Ind Crop Prod 20:131-141

Chamorro S, Monsalvez E, Piña B, Olivares A, Hernández V, Becerra J, Vidal G (2013) Analysis of aryl hydrocarbon receptor ligands in kraft mill effluents by a combination of yeast bioassays and CG-MS chemical determinations. J. Environ Sci Health A 48:1-7

Chandra R, Abhishek A (2011) Bacterial decolorization of black liquor in axenic and mixed condition and characterization of metabolites. Biodegrade 22:603-611

Chandra R, Abhishek A, Sankhwar M (2011) Bacterial decolorization and detoxification of black liquor from rayon grade pulp manufacturing paper industry and detection of their metabolic products. Bioresour Technol 102:6429-6436

Das MT, Budhraja V, Mishra M, Thakur IS (2012) Toxicological evaluation of paper mill sewage sediment treated by indigenous dibenzofuran-degrading Pseudomonas sp. Bioresour Technol 110:71-78

Forney LJ, Reddy CA (1979) Bacterial degradation of kraft lignin. Develop Ind Microbiol 20:163-175

Gupta VK, Minocha AK, Jain N (2001) Batch and continuous studies on treatment of pulp mill wastewater by Aeromonas formicans. J Chem Technol Biotechnol 76:547-552

Jiranuntipon S, Chareornwattana S, Damronglerd S, Albasi C (2008) Decolorization of synthetic melanoidins-containing wastewater by a bacterial consortium. J Ind Microbiol Biotechnol 38:1313-1321

Khalid A, Arshad M, Crowley DE (2009) Biodegradation potential of pure and mixed bacterial cultures for removal of 4-nitroaniline from textile dye wastewater. Water Res 43:1110-1116

Kirk TK, Schulz E, Connor WL, Lorenz LF, Zeikus JG (1978) Influence of cultural parameters on lignin metabolism by Phanerochaete chrysosporium. Arch Microbiol 117:227-287

Ko JJ, Shimizu Y, Ikeda K, Kim SK, Park CH, Matsui S (2009) Biodegradation of high molecular weight lignin under sulfate reducing condition: lignin degradability and degradation byproducts. Bioresour Technol 100:1622-1627

Ksibi MM, Amor SB, Elaloui Cherif S, Houas EA, Elaloui M (2003) Photodegradation of lignin from black liquor using $\mathrm{UV} / \mathrm{TiO}_{2}$ system. J Photochem Photobiol A: Chem 154:211-218 
Lee YCM, Wang CC (2006) Isolation and physiological characterization of the pentachlorophenol degrading bacterium Sphingomonas chlorophenolica. Chemosphere 62:709-714

Lee J, Koh D, Andijani M, Saw SM, Munoz C, Chia SE, Wong ML, Hong CY, Ong CN (2002) Effluents from a pulp and paper mill: a skin and health survey of children living in upstream and downstream villages. Occup Environ Med 59:373-379

Masai E, Shinohara S, Hara H, Nishikawa S, Katayama Y, Fukuda M (1999) Genetic and biochemical characterization of a 2-pyrone4, 6-dicarboxylic acid hydrolase involved in the protocatechuate 4, 5-cleavage pathway of Sphingomonas paucimobilis SYK-6. J Bacteriol 181:55-62

Morii H, Nakamiya K, Kinoshita S (1995) Isolation of lignin decolourising bacterium. J Ferment Bioeng 80:296-299

Perestelo F, Falcon MA, Perez ML, Roig EC, de la Fuente Martin G (1989) Bioalteration of kraft pine lignin by Bacillus megaterium isolated from compost piles. J Ferment Bioeng 68:151-153
Raj A, Reddy MMK, Chandra R (2007) Identification of low molecular weight aromatic compounds by gas chromatographymass spectrometry (GC-MS) from kraft lignin degradation by three Bacillus sp. Int Biodeterior Biodegrade 59:292-296

Shin KS, Lee YJ (1999) Depolymerization of lignosulfonate by peroxidase of the white-rot basidiomycetes, Pleurotus ostreatus. Biotechnol Lett 21:585-588

Singhal A, Thakur IS (2009) Decolourization and detoxification of pulp and paper mill effluent by Cryptococcus sp. Biochem Eng J 46:21-27

Ugurlu M, Gurses A, Dogar C, Yalcin M (2008) The removal of lignin and phenol from paper mill effluents by electro-coagulation. J Environ Manage 87:420-428 